\title{
Missed opportunities to keep children safe? National survey of injury prevention activities of children's centres
}

Michael C. Watson ${ }^{a}$, Caroline Mulvaney ${ }^{a}$, Clare Timblina, Jane Stewart $^{\mathrm{a}}$, Carol Coupland $^{\mathrm{a}}$, Toity Deave ${ }^{\mathrm{b}}$, Mike Hayes ${ }^{\mathrm{c}}$ and Denise Kendrick ${ }^{\mathrm{a}}$

${ }^{a}$ Faculty of Medicine and Health Sciences, University of Nottingham, Nottingham UK. ${ }^{b}$ Centre for Child \& Adolescent Health, University of the West of England, Bristol, UK 'The Child Accident Prevention Trust (CAPT), London, UK

\section{Abstract \\ Objective.}

To ascertain the activities undertaken by children's centres to prevent unintentional injuries in the under-fives and, in particular, the prevention of falls, poisoning and scalds.

\section{Design.}

A questionnaire was posted to managers of 851 children's centres, using stratified cluster sampling. The questionnaire included questions on injury prevention activities undertaken by the centre, knowledge and attitudes to injury prevention, partnership working, and barriers and facilitators to injury prevention.

\section{Setting.}

England, United Kingdom.

Results.

A response rate of $61 \%$ was achieved. Most respondents (98\%) agreed that children's centres can be effective in preventing accidents. Over half the respondents (59\%) did not know if there was an injury prevention group in their area, and $22 \%$ did not know if there was a home safety equipment scheme. Only $12 \%$ knew the major cause of injury deaths in children under five. A variety of activities were being undertaken including one to one advice and issuing leaflets. However, for some important topics such as baby walkers, and disposal of unwanted medicines no advice was being provided in some areas. Lack of funding (52\%) and lack of capacity (39\%) were the most common reasons cited as barriers to injury prevention activities.

\section{Conclusions.}

Injury prevention is an important activity undertaken by children's centres. Given their position in the heart of the community their potential as an agency to prevent injuries has been highlighted and recommended. Further support and resource will be needed if they are to fully develop their potential in preventing unintentional injuries in the home.

Keywords: children's centres, injury prevention, national survey, England

\section{Corresponding author:}

Michael Craig Watson, Faculty of Medicine and Health Sciences, School of Health Sciences, University of Nottingham, Queen's Medical Centre, Nottingham NG7 2HA, UK.

E-mail: Michael.Watson@nottingham.ac.uk 


\section{Introduction}

Child unintentional injuries are an important global public health problem and are a major cause of mortality and disability in the under-fives (Peden $\mathrm{M}$ et al., 2008). Although the burden of childhood injuries is greatest in low income countries, it is important to note that within each country, injuries disproportionately affect children from low income families (Peden $\mathrm{M}$ et al., 2008). In the UK, there are steep social gradients in injury mortality and morbidity for a range of injury mechanisms (Edwards P et al., 2006; Hippisley-Cox et al., 2002; Lyons et al., 2003; Roberts and Power, 1996; Roberts, 1997). The majority of injuries in the under-fives occur at home and falls are the most common injury (Morrison et al., 1999; British Medical Association, 2001; Public Health England, 2014).

To address this challenge, the Department of Health's Healthy Child Programme provides guidance on a range of health topics including injury prevention and identifies children's centres as key to supporting the programme (Department of Health, 2009). Additionally, the National Institute for Health and Care Excellence (NICE) has published guidance on the prevention of unintentional injuries among children and recommendations include: prioritising households at greatest risk with home safety assessments, advice and referral to safety equipment schemes; and, partnership approaches (National Institute for Health and Clinical Excellence, 2013; National Institute for Health and Clinical Excellence, 2010b; National Institute for Health and Clinical Excellence, 2010a). The guidance is targeted at a wide range of groups and organisations including health services, local authorities, health and wellbeing boards and children's centres. More recently, Public Health England has highlighted both: the key child injury areas that they think should be prioritised; and research based interventions that are available (Public Health England, 2014).

Children's centres were established across England starting in 2004 to improve health and educational outcomes for children (Children Schools and Families Committee, 2010). They are now managed by or on behalf of, or under arrangements with, local authorities. In 2013, a new "core purpose" for children's centres was developed: "to improve outcomes for young children and their families and reduce inequalities between families...." (Department for Education, 2013). One analysis suggests that every year over one million families are being supported by children's centres (4Children, 2013). Children's centres thus have the remit and potential to make significant contributions to this important public health issue, particularly among the most disadvantaged.

There are now numerous publications reporting the development and impact of children's centres (Children Schools and Families Committee, 2010; Melhuish et al., 2010; Melhuish et al., 2008; Hutchings et al., 2007; The National Evaluation of Sure Start Research Team, 2008; Department for Education, 2010; Baggott, 2011; Avis et al., 2007; MacNeill, 2009; House of Commons Education Committee, 2014; Goff et al., 2013). However, their role in injury prevention has received little attention in the literature. Our research seeks to address this gap, consisting of national injury prevention surveys at two points in time. Our first survey had a fire prevention focus (Watson et al., 2014), while this second study aims to describe and quantify the injury prevention activities focussing on the prevention of falls, poisoning and scalds being undertaken by children's centres across England. 


\section{Methods}

The survey comprised questions taken from previous injury prevention surveys targeting professional groups (Watson and White, 2001; Kendrick et al., 2003; Watson et al., 2007), accompanied by questions designed by the research study team. Content validity was assessed by experts within the research study team (Litwin, 1995) and face validity was assessed by members of staff at the University of Nottingham who had no injury prevention training. Questions were structured according to standard principles of questionnaire design, together with advice from experts and piloting (Oppenheim, 1992; Salant and Dillman, 1994). The survey was piloted with managers from 10 children's centres that were not included in the sample, with minor modifications made after piloting.

The questionnaire consisted of 10 open-ended and closed questions to gather information about characteristics of the children's centres, health priority areas, injury prevention activities, knowledge and attitudes towards injuries and their prevention, barriers and facilitators to injury prevention activity and partnership working. The questionnaire was developed for individuals responsible for the day-to-day management and running of children's centres.

\section{Sample size}

We calculated that responses would be required from a total of 314 children's centres from 25 Primary Care Trusts (PCTs) to estimate the proportions of positive responses to a number of questions relating to injury prevention activity to within +/- 7\% (95\% confidence interval), based on responses to questions in a previous survey (Kendrick et al., 2003). This calculation accounted for clustering of children's centres within PCTs, assuming an ICC of 0.05 , an average of 20 children's centres per $\mathrm{PCT}$, and an estimated $65 \%$ response rate such that an average of 13 children's centres per PCT would respond to the questionnaire.

\section{Survey distribution}

Stratified cluster sampling was used. A list of children's centres in England was obtained from the Department for Education in November 2011. Three PCTs were selected at random from each Strategic Health Authority $(\mathrm{SHA}, \mathrm{n}=10$ ) and all children's centres $(n=851)$ within the sampled PCTs were invited to participate. Questionnaires, together with a covering letter and freepost reply envelope, were posted in January 2012. Questionnaires were addressed to the children's centre manager, rather than a named contact, with the aim of ensuring questionnaires were opened and forwarded if appropriate. To improve the response rate, managers received three further reminder questionnaires at two week intervals (McColl et al., 2001; Edwards et al., 2002).

\section{Data entry and analysis}

All data were double entered and two separate operators keyed every questionnaire. The two datasets were then compared and one master file created. Discrepancies were manually corrected after referring back to the questionnaire. Data were analysed using Stata SE 11.0. Binary and categorical variables were summarised using frequencies and proportions. Responses to open questions were categorised by generating a coding list and assigning responses to categories. 


\section{Ethics}

Approval for the study was granted by North Nottinghamshire Research Ethics Committee (study reference number $=09 / \mathrm{H0407} / 44$ ).

\section{Results}

A total of 526 questionnaires were returned, of which nine were blank. Of 851 questionnaires posted, eight were returned undelivered, giving a response rate of $61.3 \%$ (517/843). It should be noted that some children's centre managers manage more than one centre.

\section{Priority areas}

Overall, of the 485 children's centres managers responding, 63.5\% ( $n=308)$ considered injury prevention to be one of the three main priority areas for children's health for their centre. Other topics listed in their top three priorities included 'healthy diet/healthy lifestyle' (84.5\%, $n=410)$, 'breastfeeding' $(39.0 \%, n=189)$, 'child protection' (19.2\%, $n=93)$, 'mental health/emotional well-being' (18.8\%, $n=91)$, 'dental health' $(7.4 \%, n=36)$ and 'speech/language/literacy/communication' (12.6\%, $n=61)$.

\section{Strategies}

Just under half of respondents $(n=198,42.3 \%)$ reported that their centre had a written child injury prevention strategy, $47.4 \%(n=222)$ stated that their centre did not, and $10.3 \%(n=48)$ did not know.

In addition, $32.8 \%$ respondents stated that their Local Authority had a written strategy and $22.0 \%$ said their PCT had a written strategy. The majority of respondents did not know whether their Local Authority or PCT had a strategy ( $n=308,64.8 \%$ and $n=337,74.1 \%$, respectively).

\section{Knowledge and attitudes}

Knowledge of the main cause of child injury deaths in the under-fives in the home was poor, only $11.7 \%$ of respondents $(n=51)$ correctly identified choking and suffocation. One quarter of respondents $(24.5 \%, n=107)$ thought falls was the main cause of child injury deaths. Almost half of respondents $(47.4 \%, n=211)$ knew that falls were the major cause of non-fatal unintentional injuries to children under five in the home.

Table 1 shows responses to questions about attitudes towards injury prevention. While $81.3 \%$ of respondents agreed or strongly agreed that injury prevention is predominantly the responsibility of the parent/carer, nearly all respondents (98.2\%) agreed or strongly agreed that children's centres can be effective in preventing accidents.

\section{INSERT Table 1 about here}

\section{Activities}

Overall, $98.0 \%(n=499)$ stated that their centre was involved in some form of injury prevention activity. While nearly all displayed posters on child safety ( $n=501,97.7 \%$ ) 
and took part in Child Safety Week ( $n=461,90.4 \%)$, fewer were involved in media work $(n=79,15.8 \%)$. Almost a third $(n=157,31.3 \%)$ lobbied or campaigned on local safety issues. However, many centres ( $n=403,79.2 \%$ ) had invited outside speakers to talk to parents and had collected data on children's accidents ( $n=403,79.2 \%)$.

Centre managers were asked how they provided advice in relation to falls, scalds and poisoning prevention: they provided this in various forms (Table 2). Topics they were least likely to provide advice on were: non-slip bath mats (22.2\%); disposal of unwanted medicines (22.4\%); poisonous plants (25.0\%); and thermostatic mixer valves (38.1\%).

\section{INSERT Table 2 about here}

Centre managers were asked if there was a home safety equipment scheme in their area and a total of $42.0 \%(n=217)$ reported that a scheme was in operation, however, $21.7 \%(n=112)$ did not know. Just over a quarter of these schemes were reported as being led by the children's centre $(28.6 \%, n=59)$ with $10.2 \%(n=21)$ run by the Local Authorities and $8.3 \%(n=17)$ run by RoSPA, as part of the 'Safe At Home' national scheme. The majority of schemes $(59.8 \%, n=128)$ provided equipment free while $34.1 \%(n=73)$ provided low cost equipment and $4.7 \% \quad(n=10)$ loaned equipment. In addition, over half of schemes (55.3\%, $n=114$ ) fitted equipment.

The types of equipment provided by home safety equipment schemes included safety catches for drawers and cupboards $(74.0 \%, n=111)$, table corner covers $(67.5 \%, n=104)$, safety gates $(63.3 \%, n=95)$, fridge locks $(52.3 \%, n=78)$, devices to measure bath water temperature $(51.0 \%, n=76)$ and window locks $(46.6 \%, n=69)$. Fewer schemes provided first aid kits $(29.4 \%, n=42)$ and lockable medicine cupboards $(10.5 \%, \mathrm{n}=15)$.

\section{Working together}

Only $13.5 \%(n=68)$ of respondents knew of an organised group specifically for child injury prevention in their area; the majority $(58.9 \%, n=296)$ did not know whether there was such a group.

Children's centres managers reported that their centres frequently refer families to organisations for home safety checks $(53.1 \%, 251 / 473)$, safety equipment schemes $(47.4 \%, 221 / 466)$, and to pharmacists for the safe disposal of unwanted medicines $(48.7 \%, 230 / 472)$. Few centres refer families to an organisation for a thermostatic mixer valve $(2.8 \%, 13 / 461)$. Most frequently, families were referred to fire and rescue services for a home safety check $(61.6 \%, 122 / 198)$.

\section{Barriers and enabling factors to injury prevention work}

The main barriers and enabling factors to injury prevention activities reported by the children's centre managers are shown in Table 3. Among the 417 reporting barriers, lack of funding (51.8\%), lack of capacity in terms of staff time $(38.8 \%)$, and difficult to access certain families (26.1\%) were the three most frequently mentioned barriers. In terms of enabling factors, of the 312 reporting enabling factors, the three most frequently mentioned factors were access to families (38.8\%), working with other agencies (34.9\%), and availability of leaflets to distribute $(25.0 \%)$. 


\section{INSERT Table 3 about here}

\section{Discussion}

\section{Main findings of this study}

The findings from this second national survey provide data on unintentional injury prevention activities undertaken within children's centres and the knowledge and attitudes of managers towards unintentional injuries and their prevention. Children's centre managers had positive attitudes towards injury prevention; however, they had many gaps in knowledge both about local initiatives and injury prevention in general. Moreover, for some managers the priority given to this topic and the activities undertaken did not appear to match recent guidance (National Institute for Health and Clinical Excellence, 2010a; National Institute for Health and Clinical Excellence, 2010b; National Institute for Health and Clinical Excellence, 2013; Public Health England, 2014).

\section{What is already known on this topic}

The first national survey of injury prevention activities of children's centres found that the majority of children's centre managers were unaware of injury prevention activities such as organised injury prevention partnerships in their local area; and, their knowledge in relation to some areas of injury prevention was poor (Watson et al., 2014). Similarly the majority of managers in the current study were unaware of important injury prevention initiatives and only $12 \%$ could correctly identify the main cause of child injury deaths in the under-fives in the home.

An important guide for local planning of child unintentional injuries in the home is NICE PH30 (National Institute for Health and Clinical Excellence, 2010a). Its recommendations include: working in partnership; and, ensuring families with children at high risk of injury are provided with home safety assessments and advice and referred to safety equipment schemes. It is of concern that one fifth of managers in this and the earlier survey did not know if there was a safety equipment scheme in their area.

Although some joint work is occurring with other agencies the children's centres appear to be collaborating with individual organisations rather than being part of multi-agency partnerships that are recommended in recent and past injury prevention guidance (Public Health England, 2014; Audit Commission/Health Care Commission, 2007). It should be noted that partnership work has also been recommended for many decades, as a cornerstone of effective health promotion (World Health Organization, 1986; Scriven, 1998; Green J et al., 2015). However, productive partnership work is a complex process and requires a wide range of skills and a great deal of commitment (Scriven, 1998; Watson, 1994; Department of Health, 1993). Children's centres are going to need help in developing and sustaining effective child injury prevention alliances. The Child Accident Prevention Trust (CAPT) and the Royal Society for the Prevention of Accidents (RoSPA) have considerable expertise in this area and have in the past promoted and supported many local alliances. In some areas public health specialists from local authorities are also involved in actively supporting such alliances. 
In relation to the priority given to child injury prevention work in the home and the main barriers to working in this area, there were also similarities between this survey and our earlier one (Watson et al., 2014). In the initial survey, only 58\% considered injury prevention to be one of the three main priority areas for children's health for their centre, similarly in this survey the figure was $64 \%$. In both surveys lack of funding and lack of capacity were stated as the two main barriers to work in this area.

The current survey concentrated on falls, poisoning and scald prevention in the home. Although, we found evidence of various activities including one to one advice and the issuing of leaflets, in many areas centres did not appear to be undertaking activities that have been recommended based on the evidence of effectiveness (National Institute for Health and Clinical Excellence, 2013; National Institute for Health and Clinical Excellence, 2010a). In addition, for some important topics such as baby walkers, disposal of unwanted medicines and thermostatic mixing valves no advice was being provided in some areas. It is noteworthy that CAPT and RoSPA websites provide accurate information about national guidance and effective interventions for specific child home safety topics.

In recent guidance for local authorities and partnerships, Public Health England has recommended that "a senior manager is designated lead for child injury prevention, and that the development of a local strategy is directed by an appropriate board such as the health and wellbeing board" (Public Health England, 2014). Such a manager could ensure that staff in children's centres have the right level of knowledge, skills and awareness about specific injury prevention activities and partnerships in their area.

\section{Limitations of this study}

One weakness of this study is that the data collected was self-reported. However, considerable care was taken in the design of the questionnaire, including using questions, where possible, that had been published in articles in peer-reviewed journals, undertaking a pilot study, and using the expertise within the research team to critique the data collection tool in terms of relevance and validity.

Although the response rate for this survey is comparable to a previous survey of children's centres (Tanner E et al., 2012) and higher than others (4Children, 2012; 4Children, 2013; Watson et al., 2014), a response rate of $61 \%$ does raise the possibility that non-response bias may have occurred, that is, those responding may have been more interested in this topic and also may have been more likely to undertake injury prevention activities. If this is the case, the findings may overestimate the injury prevention activity being undertaken by children's centres, but this would not alter our conclusions.

\section{Conclusion}

This paper presents the findings from the second national survey of unintentional injury prevention activities taking place in children's centres. There appears to have been little progress over the two years since the initial survey. Although managers still have positive views about potential injury prevention roles and they are currently undertaking a variety of interventions, their activities do not appear to be 
in line with national guidance. Children's centres in England are going to need considerable support to fully develop their potential in preventing unintentional injuries in the home. 


\section{References please show all Journal titles in full}

4Children. (2012) Sure Start Children's Centres Census 2012. Developments, trends and analysis of Sure Start Children's Centres over the last year and the implications for the future, London: 4Children.

4Children. (2013) Children's Centres Census 2013. A national overview of developments in Children's Centres. London: 4Children.

Audit Commission/Health Care Commission. (2007) Better safe than sorry: preventing unintentional injury to children. London: Audit Commission.

Avis M, Bulman D and Leighton P. (2007) Factors affecting participation in Sure Start programmes: a qualitative investigation of parents' views. Health \& Social Care in the Community 15: 203-211.

Baggott R. (2011) Public Health Policy \& Politics. Basingstoke: Palgrave Macmillan.

British Medical Association. (2001) Injury Prevention London: BMA.

Children Schools and Families Committee. (2010) Fifth Report of Session 2009-10, Sure Start Children's Centres, HC 130-I. London: Stationery Office.

Department for Education. (2010) Sure Start Children's Centres Statutory Guidance London: Department for Education.

Department for Education. (2013) Sure Start children's centres statutory guidance. For local authorities, commissioners of local health services and Jobcentre Plus, London: Department for Education.

Department of Health. (1993) Working Together for Better Health, London: Department of Health.

Department of Health. (2009) Healthy Child Programme. Pregnancy and the first five years of life. London: Department of Health.

Edwards P, Roberts I, Green J, et al. (2006) Deaths from injury in children and employment status in family: analysis and trends in class specific death rates. British Medical Journal 313: 784-786.

Edwards P, Roberts I, Clarke M, et al. (2002) Increasing response rates to postal questionnaires: systematic review. British Medical Journal 324: 1183-1190.

Goff J, Hall J, Sylva K, et al. (2013) Evaluation of Children's Centres in England (ECCE) - Strand 3: Delivery of Family Services by Children's Centres Research Report. DfE Research Report No. DFE-RR297. London: DfE.

Green J, Tones K, Cross R, et al. (2015) Health Promotion Planning and Strategies. London: Sage.

Hippisley-Cox J, Groom L, Kendrick D, et al. (2002) Cross sectional survey of socioeconomic variations in severity and mechanism of childhood injuries in Trent 1992-7. British Medical Journal 324: 1132.

House of Commons Education Committee. (2014) Foundation Years: Sure Start children's centres. Fifth Report of Session 2013-14. Volume II. Oral and written evidence. London: The Stationery Office.

Hutchings J, Bywater T, Daley D, et al. (2007) Parenting intervention in Sure Start services for children at risk of developing conduct disorder: pragmatic randomised controlled trial. British Medical Journal 334: 678.

Kendrick D, Groom L, Hippisley-Cox J, et al. (2003) Accidental injury: a neglected area within Primary Care Groups and Trusts? Health Education Research 18: 380-388. 
Litwin M. (1995) How to measure survey reliability and validity. California: Sage Publications.

Lyons RA, Jones SJ, Deacon T, et al. (2003) Socioeconomic variation in injury in children and older people: a population based study. Injury Prevention 9: 33-37.

MacNeill V. (2009) Forming partnerships with parents from a community development perspective: lessons learnt from Sure Start. Health \& Social Care in the Community 17: 659-665.

McColl E, Jacoby A, Thomas L, et al. (2001) Design and use of questionnaires: a review of best practice applicable to surveys of health service staff and patients. Health Technology Assessment 5.

Melhuish E, Belsky J and Barnes J. (2010) Evaluation and value of Sure Start. Archives of Disease in Childhood 95: 159-161.

Melhuish E, Belsky J, Leyland AH, et al. (2008) Effects of fully-established Sure Start Local Programmes on 3-year-old children and their families living in England: a quasi-experimental observational study. The Lancet 372: 1641-1647.

Morrison A, Stone DH, Doraiswamy N, et al. (1999) Injury surveillance in an accident and emergency department: a year in the life of CHIRPP. Archives of Disease in Childhood 80: 533-536.

National Institute for Health and Clinical Excellence. (2010a) Preventing unintentional injuries in the home among children and young people aged under 15: home safety assessments and providing safety equipment. NICE public health guidance 30, London: NICE.

National Institute for Health and Clinical Excellence. (2010b) Strategies to preventing unintentional injuries in under 15s. NICE public health guidance 29., London: NICE.

National Institute for Health and Clinical Excellence. (2013) Strategies to prevent unintentional injuries among children and young people aged under 15: Evidence Update February 2013, London: NICE.

Oppenheim A. (1992) Questionnaire Design, Interviewing and Attitude Measurement. London: Continuum.

Peden M, Oyebite K, Ozanne-Smith J, et al. (2008) World Report on Child Injury Prevention. Geneva Switzerland.

Public Health England. (2014) Reducing unintentional injuries in and around the home among children under five years. London: Public Health England.

Roberts I. (1997) Cause specific social class mortality differentials for child injury and poisoning in England and Wales. Journal of Epidemiology and Community Health 51: 334-335.

Roberts I and Power C. (1996) Does the decline in child injury mortality vary by social class? A comparison of class specific mortality in 1981 and 1991. BritishMedical Journal 313: 784-786.

Salant P and Dillman D. (1994) How to conduct your own survey. Chichester: John Wiley \& Sons.

Scriven A. (1998) Alliances in Health Promotion. London: Macmillan.

Tanner E, Agur M, Hussey D, et al. (2012) Evaluation of Children's Centres in England (ECCE) Strand 1: First Survey of Children's Centre Leaders in the Most Deprived Areas. Oxford: University of Oxford. 
The National Evaluation of Sure Start Research Team. (2008) The impact of Sure Start Local Programmes on three year olds and their families. Surestart Report 27, London: DCSF.

Watson M. (1994) Alliances against accidents. Practice Nursing 5: 20.

Watson M, Kendrick D, Coupland C, et al. (2007) Childhood injury prevention: The views of health visitors and nursery nurses working in deprived areas. International Journal of Health Promotion \& Education 45: 4-10.

Watson M and White J. (2001) Accident prevention activities: A national survey of health authorities. Health Education Journal 60: 275-283.

Watson MC, A. Mulvaney C, Kendrick D, et al. (2014) National survey of the injury prevention activities of children's centres. Health \& Social Care in the Community 22: 40-46.

World Health Organization. (1986) Ottawa Charter for Health Promotion Copenhagen: WHO. 
Table 1 Respondents' views on child accident prevention.

\begin{tabular}{lccccc}
\hline View & $\begin{array}{c}\text { Strongly } \\
\text { agree } \\
\mathbf{N}(\%)\end{array}$ & $\begin{array}{c}\text { Agree } \\
\mathbf{N}(\%)\end{array}$ & $\begin{array}{c}\text { Disagree } \\
\mathbf{N}(\%)\end{array}$ & $\begin{array}{c}\text { Strongly } \\
\text { disagree } \\
\mathbf{N}(\%)\end{array}$ & $\begin{array}{c}\text { Not sure } \\
\mathbf{N}(\%)\end{array}$ \\
\hline $\begin{array}{l}\text { Accident prevention is } \\
\text { predominantly the responsibility of } \\
\text { the parent/carer [36] }\end{array}$ & $156(32.4)$ & $235(48.9)$ & $64(13.3)$ & $11(2.3)$ & $15(3.1)$ \\
$\begin{array}{l}\text { Most child accidents are } \\
\text { preventable [30] }\end{array}$ & $190(39.0)$ & $275(56.5)$ & $7(1.4)$ & 0 & $15(3.1)$ \\
$\begin{array}{l}\text { Children's centres can be effective } \\
\text { in preventing accidents [24] }\end{array}$ & $231(46.9)$ & $253(51.3)$ & $1(0.2)$ & $1(0.2)$ & $7(1.4)$ \\
$\begin{array}{l}\text { Other agencies have a greater } \\
\text { responsibility for accident } \\
\text { prevention than children's centres } \\
\text { [31] }\end{array}$ & $19(3.9)$ & $76(15.6)$ & $300(61.7)$ & $25(5.1)$ & $66(13.6)$ \\
[] missing data & & & &
\end{tabular}


Table 2 Advice and leaflets on falls, scalds and poisoning prevention provided by children's centres.

\begin{tabular}{|c|c|c|c|c|c|}
\hline Category & $\begin{array}{c}\text { No advice } \\
\mathrm{N}(\%)\end{array}$ & $\begin{array}{l}\text { One to one } \\
\text { advice } \\
\mathrm{N}(\%)\end{array}$ & $\begin{array}{l}\text { Advice in } \\
\text { groups } \\
\mathrm{N}(\%)\end{array}$ & $\begin{array}{l}\text { Leaflets } \\
\mathrm{N}(\%)\end{array}$ & $\begin{array}{l}\text { Don't } \\
\text { know } \\
N(\%)\end{array}$ \\
\hline \multicolumn{6}{|l|}{ Falls Prevention } \\
\hline $\begin{array}{l}\text { What to do if a child has a head } \\
\text { injury [0] }\end{array}$ & $21(4.1)$ & $268(51.8)$ & $324(62.7)$ & $255(49.3)$ & $20(3.9)$ \\
\hline Stair safety $[0]$ & $22(4.3)$ & $312(60.4)$ & $302(58.4)$ & $314(60.7)$ & $5(1.0)$ \\
\hline $\begin{array}{l}\text { Not leaving children on high } \\
\text { surfaces [0] }\end{array}$ & $25(4.8)$ & $291(56.3)$ & $301(58.2)$ & $276(53.4)$ & $7(1.4)$ \\
\hline General falls prevention [0] & $41(7.9)$ & $236(45.7)$ & $292(56.5)$ & $359(69.4)$ & $1(0.2)$ \\
\hline Tripping hazards [0] & $42(8.1)$ & $265(51.3)$ & $283(54.7)$ & $285(55.1)$ & $12(2.3)$ \\
\hline Climbing hazards [0] & $46(8.9)$ & $251(48.6)$ & $296(57.3)$ & $298(57.6)$ & $5(1.0)$ \\
\hline Window locks [0] & $56(10.8)$ & $285(55.1)$ & $266(51.5)$ & $253(48.9)$ & $9(1.7)$ \\
\hline High chair and push chair safety [0] & $69(13.4)$ & $230(44.5)$ & $243(47.0)$ & $253(48.9)$ & $22(4.3)$ \\
\hline Baby walker safety [0] & $85(16.4)$ & $217(42.0)$ & $224(43.3)$ & $219(42.4)$ & $17(3.3)$ \\
\hline Non-slip bath mats [0] & $115(22.2)$ & $212(41.0)$ & $188(36.4)$ & $195(37.7)$ & $40(7.7)$ \\
\hline \multicolumn{6}{|l|}{ Scald prevention } \\
\hline Handling hot drinks [0] & $10(1.9)$ & $274(53.0)$ & $384(74.3)$ & $349(67.5)$ & $4(0.8)$ \\
\hline General scald prevention [0] & $36(7.0)$ & $234(45.3)$ & $291(56.3)$ & $339(65.6)$ & $10(1.9)$ \\
\hline $\begin{array}{l}\text { Cooking safety } \\
\text { (cookers/microwaves) [0] }\end{array}$ & $50(9.7)$ & $241(46.6)$ & $304(58.8)$ & $265(51.3)$ & $13(2.5)$ \\
\hline Bathroom scald prevention [0] & $57(11.0)$ & $232(44.9)$ & $258(49.9)$ & $273(52.8)$ & $21(4.1)$ \\
\hline Kettle safety [0] & $57(11.0)$ & $243(47.0)$ & $280(54.2)$ & $266(51.5)$ & $25(4.8)$ \\
\hline $\begin{array}{l}\text { Thermostatic mixer valves (TMVs) } \\
{[0]}\end{array}$ & $197(38.1)$ & $89(17.2)$ & $106(20.5)$ & $99(19.2)$ & $138(26.7)$ \\
\hline \multicolumn{6}{|l|}{ Poisoning prevention } \\
\hline $\begin{array}{l}\text { Safe strage of hazardous subsatnces } \\
\text { (e.g. medicines, household } \\
\text { chemicals) [0] }\end{array}$ & $38(7.4)$ & $244(47.2)$ & $269(52.0)$ & $259(50.1)$ & $23(4.5)$ \\
\hline General poisoning prevention [0] & $61(11.8)$ & $203(39.3)$ & $225(43.5)$ & $290(56.1)$ & $21(4.1)$ \\
\hline Child resistant conainers $[0]$ & $91(17.6)$ & $201(38.9)$ & $214(41.4)$ & $214(41.4)$ & $32(6.2)$ \\
\hline Disposal of unwanted medicines [0] & $116(22.4)$ & $183(35.4)$ & $179(34.6)$ & $183(35.4)$ & $44(8.5)$ \\
\hline Poisonous plants [0] & $129(25.0)$ & $150(29.0)$ & $161(31.1)$ & $185(35.8)$ & $66(12.8)$ \\
\hline
\end{tabular}


Table 3 Barriers and enabling factors to injury prevention work in children's centres.

\begin{tabular}{lc}
\hline Barriers and enabling factors & N (\%) \\
\hline $\begin{array}{ll}\text { Barriers } \\
\text { Lack of funding }\end{array}$ & $216(51.8)$ \\
Lack of capacity/staff time & $162(38.8)$ \\
$\quad$ Difficult to access certain families & $109(26.1)$ \\
Lack of staff training/knowledge & $62(14.9)$ \\
Discontinuation of home safety equipment schemes such as & $36(8.6)$ \\
RoSPA Safe At Home & \\
Lack of data & $27(6.5)$ \\
Language problems/poor literacy & $22(5.3)$ \\
Lack of space to store equipment/ display leaflets & $21(5.0)$ \\
$\quad$ Lack of multi-agency working/lack of information sharing & $20(4.8)$ \\
between agencies & \\
& \\
\hline Enabling factors & $121(38.8)$ \\
Access to families/ accessible to families/ good relationships & \\
with families & $109(34.9)$ \\
Working with other agencies & $78(25.0)$ \\
Availability of leaflets to distribute & $67(21.5)$ \\
Trained, knowledgeable staff & $63(20.2)$ \\
Availability of free/low cost home safety equipment & $56(17.9)$ \\
\hline Dedication/commitment of staff &
\end{tabular}

